\title{
Performance of fast, medium and slow growing broilers in indoor and free-range production systems
}

\author{
M. Sarica ${ }^{1}$, U.S. Yamak ${ }^{1}$, M.A. Boz ${ }^{2}$, K. Erensoy ${ }^{1 \#}$, E. Cilavdaroglu ${ }^{3} \&$ M. Noubandiguim ${ }^{4}$ \\ ${ }^{1}$ Deparment of Animal Science, Agricultural Faculty, Ondokuz Mayis University, Samsun, Turkey \\ ${ }^{2}$ Deparment of Animal Science, Agricultural and Natural Science Faculty, Bozok University, Yozgat, Turkey, \\ ${ }^{3}$ Graduate School of Sciences, Agricultural Faculty, Deparment of Animal Science, Ondokuz Mayis University, Samsun, \\ Turkey, \\ ${ }^{4}$ Graduate School of Sciences, Faculty of Art and Science, Deparment of Biology, Ondokuz Mayis University, Samsun, \\ Turkey
}

(Received 29 March 2019; Accepted 11 October 2019; First published 31 January 2020)
Copyright resides with the authors in terms of the Creative Commons Attribution 4.0 South African Licence.
See: http://creativecommons.org/licenses/by/4.0/za
Condition of use: The user may copy, distribute, transmit and adapt the work, but must recognise the authors and the South African Journal of Animal Science.

\begin{abstract}
This study compared growth and carcass traits of 2 medium-growth crossbred, 4 slow-growth crossbred, 1 commercial slow-growth and 1 commercial fast-growth broiler strains raised in indoor and freerange production systems. One hundred twenty chicks of each strain were raised in each production system. Chicks were raised in indoor pens at a density of 10 chicks per $\mathrm{m}^{2}$. From day 29 until slaughter at 84 days of age, chicks in the free-range system were given outdoor access through doors that were open between 8.00 - 17.00 hours. The study found live weight, feed efficiency, and mortality were significantly affected by strain. However, no significant differences were found between the production systems. Outdoor access varied significantly among strains, with the commercial high-growth and medium-growth crossbred strains making less use of outdoor areas. In terms of performance traits, none of the strains showed any significant differences in performance between the indoor and free-range production systems. However, significant differences among the strains in carcass traits, $\mathrm{pH}$, and colour values of thigh and breast meat were observed in connection with differences in growth rate. Moreover, carcass and breast yields were greater in fast and medium-growth broilers, while ratios of edible inner organs were greater in medium and slow-growth broilers.
\end{abstract}

Keywords: abdominal fat, animal welfare, breast to thigh ratio, feed efficiency, outdoor access, slaughter and carcass traits

${ }^{\#}$ Corresponding author: kadir.erensoy@omu.edu.tr

\section{Introduction}

Throughout the world there has been increasing interest in alternative poultry production systems that meet higher standards for animal welfare. Some consumers prefer poultry produced in free-range systems rather than indoor systems (Who-Ming et al., 2018). Not only do consumers believe that free-range systems ensure animal welfare, they also claim they result in better tasting meat (Bessei, 2006; Wang et al., 2009; Mikulski et al., 2011). Slow-growth broiler chicks represent another alternative to organic poultry production, whose greater feed costs and production requirements result in greater overall costs (Sarica et al., 2016).

Different forms of free-range production systems are found in the US and EU as well as in China and other Far East countries, with variations observed in poultry house characteristics as well as in the freerange area available to chicks. Free-range systems offer an alternative to the high-capacity houses and high animal density of conventional production systems, which create stress that has negative effects on behavioral and physiological traits (Jones \& Millis, 1999), restrict animal movement (Marin et al., 2001), and lower performance (Mendl, 1999). Wang et al. (2009) have reported that outdoor production systems contribute to a decrease in stress and improvements in animal comfort and welfare when compared to systems that restrict outdoor access. Forage plants, animal organisms, insects, gravel and stone in the outdoor environment also have positive effects on animal digestive tracts (Sarica et al., 2011). Moreover, numerous studies have reported positive changes in taste related to improvements in certain carcass traits 
occurring when broilers are given outdoor access (Lewis et al., 1997; Fanatico et al., 2006; Fanatico et al., 2007; Van Loo et al., 2010; Hardy et al., 2013, Martinez-Perez, 2017).

How chicks perform in free-range systems varies according to factors such as genotype, age, gender, feeding regimen, stocking density, indoor and outdoor climate conditions, frequency and amount of outside access, and pasture intake levels (Gordon \& Charles, 2002; Chen et al., 2013; Spencer, 2013; Who-Ming et al., 2018). Many poultry producers have come to prefer fast-growing broiler strains for their greater breastmeat yields, more uniform carcass characteristics and greater feed efficiency when compared to slowergrowing breeds (Who-Ming et al., 2018). Fast- and medium-growth rate broilers are less likely to make use of outside access and thus benefit less from grass and other feed sources (Yang \& Jiang, 2005; Sekeroglu et al., 2009). Additionally, high levels of humidity in the outdoor environment can lead to increases in foot-pad dermatitis and other foot disorders (Boz et al., 2017). The greatest disadvantage of free-range production is the risk of epidemic disease transmission, and many studies have reported increases in the incidence of bacterial infections in broiler chickens reared in free-range systems (Rodenburg et al., 2008; Tuyttens et al., 2008; Fossum et al., 2009; Widowski et al., 2013).

In spite of these disadvantages, the free-range system continues to offer an efficient method of chicken production with a variety of alternatives that hold promise for the future (Yang \& Jiang, 2005; Sarica \& Yamak, 2010). In addition to the use of commercial broiler chicks (Mueller et al., 2018), commercial laying hens and their males, hybrid strains, and local breeds are increasingly being used in free-range production systems (Yamak et al., 2014; Martinez-Perez et al., 2017; Semwogerere et al., 2018; Devatkal et al., 2018; Cruz et al., 2018a; Tasoniero et al., 2018).

The primary objective of this study was to evaluate the performance of eight broiler strains that differed in growth potential with two production systems, Growth, feed consumption, carcass yields, some quality traits, and outdoor access rates of commercial slow- and fast-growing broiler chickens, as well as crossbreds that had been selected for different growth rates when reared in indoor and free-range production systems were evaluated.

\section{Materials and Methods}

This study was conducted at the Ondokuz Mayis University Faculty of Agriculture's Research Farm between April and August 2012. All procedures were approved by the Ondokuz Mayis University Animal Care and Use Ethic Committee. A fast-growth strain (FG) ROSS 308 (Aviagen Group, Huntsville, Alabama, USA), Rhode Island Red (RIR), Barred Plymouth Rock (BAR) and a commercial slow-growing strain (CS) (SASSO, Hubbard SAS, France) were parent stocks for the strains that were studied. The broiler strains included 2 medium-growth crossbreds [M1: FG $\times$ RIR; and M2: FG $\times$ (BAR $\times$ FG)], 4 slow-growth crossbreeds [S1: (FG x RIR); S2: (FG x BAR); S3: (FG x RIR) x RIR; S4: (FG x BAR) x BAR] (Yamak et al., 2014); 1 commercial slow-growth broiler (CS) and 1 commercial fast-growth broiler (FG).

A total of 2000 mixed-sex chicks were raised in 8 pens, with wing bands attached to chicks at 3 days of age. On day 29, 240 chicks of each strain were selected and assigned to one of two production systems (indoor and free-range), with 120 chicks (3 replications of 20 males and 20 females) per system. Chicks were raised in a conventional poultry house with a concrete floor at a stocking density of $10 \mathrm{birds} / \mathrm{m}^{2}$. The house was divided into pens separated by $2 \times 2 \mathrm{~cm}$ wire mesh. Each pen contained 3 round feeders, 2 round drinkers, and 8-cm-thick wood shavings used as litter. Ventilation and cooling were provided by small windows and fans, heating was provided by infra-red and solid-fuel-burning heaters, and white bulbs were used for lighting. A 24-hr lighting regime was applied during the first 3 days. Lighting was incrementally decreased to $20 \mathrm{~h}$ between days 4-14 and then remained constant until 6 weeks, after which natural lighting (approx:14 h/day) was applied. Starting on day 29, chicks in the free-range treatment were given access to an outdoor unit through doors that remained open between 8.00 and 17.00 hours. Each outdoor unit consisted of a $40-\mathrm{m}^{2}$ area and ground vegetation consisting of a mix of Medicago sativa and Lolium perenne maintained through irrigation.

Feed and water were provided ad libitum. Feed content varied with age and consisted mainly of layertype feed in order to achieve a less than maximum rate of growth (Table 1). All diets were formulated to provide adequate nutrient levels as defined by the NRC (1994). Chicks were vaccinated against Newcastle, Gumboro and Infectious Bronchitis diseases, and no health problems were observed during the experiment.

Data was collected on live weight, feed consumption, feed efficiency and mortality rates and calculated for each replication. Since outdoor access was provided during daylight hours starting on day 29, data recording began on day 35 and continued weekly until slaughter at the age of 84 days. At day 84,5 males and 5 females per pen were randomly selected and slaughtered after an 8-h fasting period. Birds were weighed individually and cut by manual exsanguination. Semi-automated equipment was used for scalding (1 min. at $56{ }^{\circ} \mathrm{C}$ ), plucking, chilling (in cold water, $5 \mathrm{~min}$. at $1-5^{\circ} \mathrm{C}$ ), vent-opening, evisceration, and airchilling $\left(12 \mathrm{~h}\right.$. at $\left.4{ }^{\circ} \mathrm{C}\right)$. 
Table 1 Nutrient composition of diets fed to broiler chicks during four phases of growth

\begin{tabular}{lcccc}
\hline Nutrients & $\begin{array}{c}\text { Broiler starter } \\
(1-7 \mathrm{~d})\end{array}$ & $\begin{array}{c}\text { Layer chick starter } \\
(8-28 \mathrm{~d})\end{array}$ & $\begin{array}{c}\text { Pullet grower } \\
(29-50 \mathrm{~d})\end{array}$ & $\begin{array}{c}\text { Pullet developer } \\
(51-84 \mathrm{~d})\end{array}$ \\
\hline Crude protein (\%) & 23.0 & 19.0 & 16.0 & 14.5 \\
ME (MJ/kg) & 12.7 & 11.7 & 11.7 & 11.5 \\
Crude fibre (\%) & 4.0 & 6.0 & 6.0 & 6.0 \\
Ca (\%) & 1.5 & 1.2 & 1.2 & 1.5 \\
Available P (\%) & 0.6 & 0.5 & 0.45 & 0.40 \\
Methionine (\%) & 1.3 & 0.9 & 0.75 & 0.65 \\
\hline
\end{tabular}

After slaughter and following chilling, abdominal fat was weighed and recorded as the ratio of fat surrounding abdominal muscles, cloaca and inner organs to live weight (Sarica et al., 2014). Carcasses were cut into parts according to standard methods, and leg (thigh and drumstick), breast and total edible inner organs (heart, liver and gizzard) weights were recorded as percentages of cold-carcass weights (Franco et al., 2013; Sarica et al., 2014). Meat pH was measured at three points on the left thigh and left breast (Model PC 510, Cyber Scan, Singapore), and meat colour $\left(L^{*}, a^{*}, b^{*}\right)$ was evaluated at two points on the left thigh and left breast (Fanatico et al., 2005) using a colorimeter (Konica Minolta Cr-400).

Data were subjected to analysis of variance (SPSS Inc. Version 16, Chicago, Illinois, USA) using a model that contained only the main effects of strain and production system. Interaction effects were not included. Treatment means were separated using Tukey's multiple range test. Single df contrasts were used to test the overall effects of genotype, production system and age at slaughter. A difference of $P<0.05$ was considered statistically significant.

\section{Results and Discussion}

The final body weight of birds raised in both conventional and specialty poultry production is generally $2.5 \mathrm{~kg}$, which results in a dressed carcass of $1.8-1.9 \mathrm{~kg}$. Depending upon diet, fast-growth broilers reach this market weight in approximately 42 - 49 days and medium or slow-growth broilers in 56 - 84 days (Gordon \& Charles, 2002). This study aimed to achieve a body weight of $2.5 \mathrm{~kg}$ in 49 days for the fast-growth FG genotype, 56 days for the medium-growth M1 and M2 strains), 70 days for the slow-growth CS commercial genotype and S1 and S2 cross-breeds, and 84 days for the slow-growth S3 and S4 crossbreeds. Significant differences were found between the live weights of different strains throughout the growth period $(P<0.05$; Figure 1, Table 2).

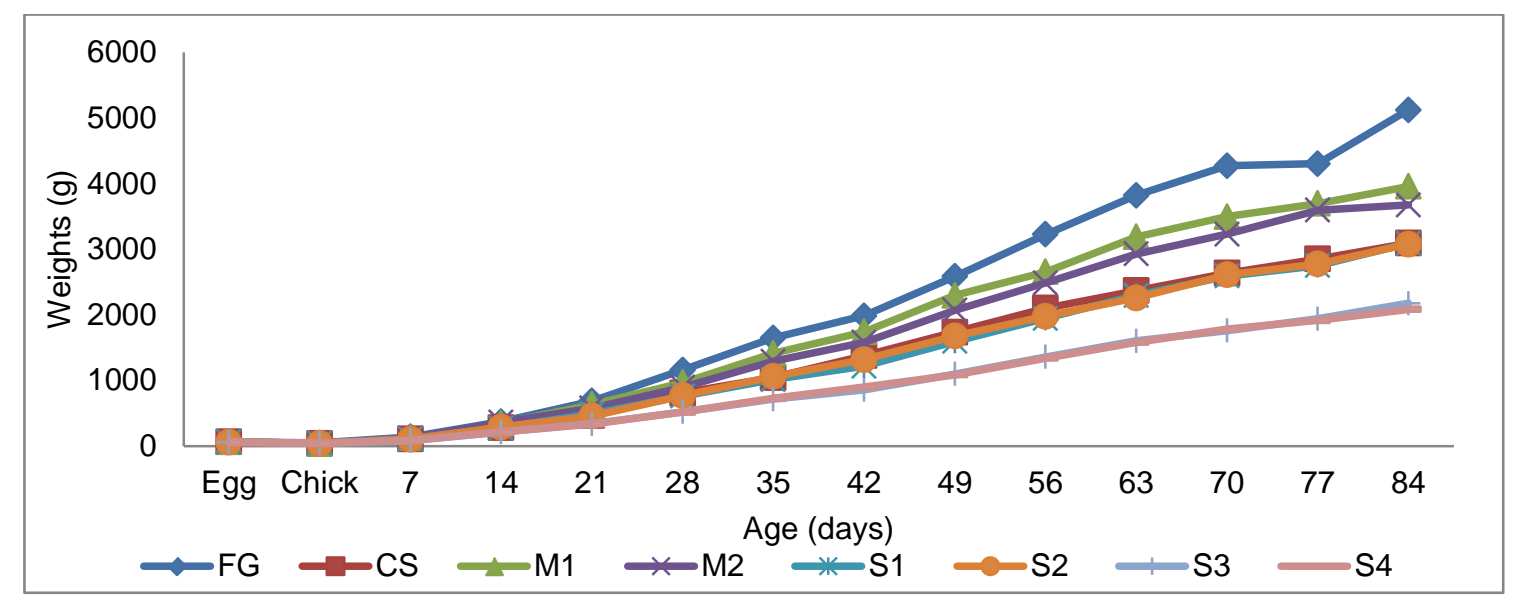

Figure 1 Egg, chick weight and live weights for each strain ${ }^{1}$ from hatching to 84 days of age

\footnotetext{
${ }^{1}$ FG: commercial fast-growth strain, CS: commercial slow-growth strain, M1: cross of FG and Rhode Island Red (RIR), M2: backcross of FG on Barred Plymouth Rock (BAR) x FG females, S1: FG x RIR, S2: FG x BAR, S3: FG x RIR crossed with RIR, S4: FG x BAR crossed with BAR
} 
Table 2 Live weights ( $\mathrm{g}$ ) attained by broilers of different strains from 35 to 84 days of age that were reared either indoors or with access to the outdoors

\begin{tabular}{|c|c|c|c|c|c|c|c|c|}
\hline \multirow{2}{*}{ Treatment $^{1}$} & \multicolumn{8}{|c|}{ Age } \\
\hline & 35 & 42 & 49 & 56 & 63 & 70 & 77 & 84 \\
\hline FG-I & $1667.3^{\mathrm{a}}$ & $2029.2^{\mathrm{a}}$ & $2626.8^{\mathrm{a}}$ & $3242.3^{\mathrm{a}}$ & $3866.5^{\mathrm{a}}$ & $4352.0^{a}$ & $4289.6^{a}$ & $5068.1^{a}$ \\
\hline FG-O & $1627.3^{\mathrm{a}}$ & $1940.8^{a}$ & $2537.3^{\mathrm{ab}}$ & $3206.1^{a}$ & $3768.7^{\mathrm{a}}$ & $4183.1^{a}$ & $4314.5^{a}$ & $5170.6^{a}$ \\
\hline CS-I & $1054.0^{\mathrm{C}}$ & $1392.0^{\mathrm{de}}$ & $1747.2^{\mathrm{e}}$ & $2058.7^{c}$ & $2374.1^{\mathrm{c}}$ & $2665.8^{c}$ & $2882.7^{\mathrm{C}}$ & $3173.3^{\mathrm{c}}$ \\
\hline CS-O & $1028.9^{C}$ & $1363.0^{\mathrm{def}}$ & $1724.1^{\mathrm{e}}$ & $2142.7^{c}$ & $2363.8^{\mathrm{C}}$ & $2604.5^{c}$ & $2834.8^{c}$ & $3014.2^{d}$ \\
\hline M1-I & $1424.5^{b}$ & $1742.2^{b}$ & $2256.5^{c}$ & $2682.3^{b}$ & $3202.6^{\mathrm{b}}$ & $3435.0^{b}$ & $3702.0^{\mathrm{b}}$ & $4033.8^{b}$ \\
\hline M1-O & $1397.9^{b}$ & $1733.1^{\mathrm{b}}$ & $2330.6^{\mathrm{bc}}$ & $2625.5^{\mathrm{b}}$ & $3169.0^{\mathrm{b}}$ & $3553.0^{\mathrm{b}}$ & $3689.3^{\mathrm{b}}$ & $3868.2^{b}$ \\
\hline M2-I & $1321.5^{\mathrm{b}}$ & $1664.7^{\mathrm{bc}}$ & $2098.4^{\mathrm{cd}}$ & $2526.4^{\mathrm{b}}$ & $3028.2^{\mathrm{b}}$ & $3190.2^{\mathrm{b}}$ & $3606.0^{\mathrm{b}}$ & $3665.7^{b}$ \\
\hline M2-O & $1264.9^{\mathrm{b}}$ & $1525.0^{\mathrm{cd}}$ & $2033.0^{d}$ & $2443.6^{b}$ & $2859.3^{b}$ & $3220.7^{b}$ & $3567.3^{\mathrm{b}}$ & $3651.3^{\mathrm{bc}}$ \\
\hline S1-I & $1044.6^{c}$ & $1217.3^{f}$ & $1615.0^{\mathrm{e}}$ & $1925.6^{c}$ & $2296.6^{c}$ & $2542.8^{c}$ & $2727.5^{c}$ & $3072.6^{d}$ \\
\hline S1-O & $945.6^{c}$ & $1213.9^{f}$ & $1550.5^{\mathrm{e}}$ & $1986.5^{c}$ & $2287.6^{c}$ & $2684.2^{c}$ & $2791.4^{c}$ & $3116.9^{d}$ \\
\hline S2-1 & $1070.9^{c}$ & $1301.1^{\mathrm{ef}}$ & $1642.0^{\mathrm{e}}$ & $1970.6^{c}$ & $2223.7^{\mathrm{C}}$ & $2550.0^{c}$ & $2656.6^{c}$ & $3084.1^{d}$ \\
\hline S2-O & $1032.6^{c}$ & $1347.7^{\mathrm{ef}}$ & $1741.7^{\mathrm{e}}$ & $2022.5^{c}$ & $2330.9^{c}$ & $2722.0^{c}$ & $2999.9^{c}$ & $3103.2^{d}$ \\
\hline S3-I & $736.7^{d}$ & $843.3^{\mathrm{g}}$ & $1089.6^{f}$ & $1373.3^{\mathrm{e}}$ & $1607.9^{d}$ & $1794.7^{d}$ & $1892.1^{d}$ & $2183.7^{\mathrm{e}}$ \\
\hline S3-O & $690.2^{d}$ & $866.8^{g}$ & $1104.8^{f}$ & $1344.9^{\mathrm{e}}$ & $1599.9^{d}$ & $1723.7^{d}$ & $1990.4^{d}$ & $2166.2^{\mathrm{e}}$ \\
\hline S4-I & $724.1^{d}$ & $903.5^{9}$ & $1142.9^{f}$ & $1313.8^{\mathrm{e}}$ & $1551.3^{d}$ & $1788.7^{d}$ & $1899.5^{\mathrm{d}}$ & $1986.4^{\mathrm{e}}$ \\
\hline S4-O & $727.8^{d}$ & $894.3^{\mathrm{g}}$ & $1056.2^{f}$ & $1343.5^{\mathrm{e}}$ & $1582.5^{d}$ & $1776.4^{d}$ & $1919.9^{d}$ & $2120.1^{\mathrm{e}}$ \\
\hline SEM & 14.06 & 17.23 & 23.23 & 28.99 & 34.58 & 36.74 & 36.17 & 45.33 \\
\hline$P$ (treatment effect) & ** & ** & ** & ** & *夫 & ** & ** & ** \\
\hline \multicolumn{9}{|l|}{ Production system } \\
\hline Indoor & 1130.5 & 1386.7 & 1777.3 & 2136.6 & 2518.9 & 2789.9 & 2957.0 & 3283.5 \\
\hline Outdoor & 1089.4 & 1360.6 & 1759.8 & 2139.4 & 2495.2 & 2808.5 & 3013.4 & 3276.3 \\
\hline$P$ & NS & NS & NS & NS & NS & NS & NS & NS \\
\hline
\end{tabular}

${ }^{1}$-I: reared indoors, -O: reared with outdoor access (Free-range), FG: commercial fast-growth strain, CS: commercial slow-growth strain, M1: cross of FG and Rhode Island Red (RIR), M2: backcross of FG on Barred Plymouth Rock (BAR) $x$ FG females, S1: FG x RIR, S2: FG x BAR, S3: FG x RIR crossed with RIR, S4: FG x BAR crossed with BAR ${ }^{\star} P<0.05,{ }^{\star \star} P<0.01, \mathrm{NS}: P>0.05$, SEM: standard error of the mean, ${ }^{\mathrm{a}-\mathrm{g}}$ : Means within a column lacking a common superscript differ $(P<0.05)$

Production system had no statistically significant effect on live weight at any point during the study $(P$ $>0.05$ ). Live weights tended to be lower in the free-range groups of the fast- and medium-growing strains FG, $\mathrm{M} 1$, and $\mathrm{M} 2$ as compared to the indoor groups, especially, once chicks reached live weights of $2 \mathrm{~kg}$ or more. By contrast, the indoor groups of the slow-growth S3 and S4 strains tended to have lower live weights than the free-range groups. Who-Ming et al. (2018) reported that live weights of broilers during spring and autumn were greater for birds that were reared in an indoor system when compared to those reared in an outdoor system. Li et al. (2017) found 90-day weights of medium-growth broiler chickens and found the birds reared indoors in pens with solid floors to be heaviest $(2434.9 \mathrm{~g})$, followed by those reared in cages $(2142.0 \mathrm{~g})$ and in the free-range production system $(2089.5 \mathrm{~g})$.

Mueller et al. (2018) reported slaughter weights of $2415 \mathrm{~g}$ at 35 days of age for the RossPM3 strain and of $2423 \mathrm{~g}, 2161 \mathrm{~g}, 1758 \mathrm{~g}$, and $1227 \mathrm{~g}$ at 63 days of age for SassoS1, Lohman dual, Belgian Malinez and Lohman Brown Plus strains, respectively. Devatkal et al. (2018) evaluated carcasses from broilers of moderate growth rate at 60 days of age, broilers of slow growth rate at 90 days of age, and fast-growing commercial broilers at 37 days of age when each strain had reached maturity. Cruz et al. (2018a) reported 6 different strains, including purebred and hybrid chickens, to reach live weights of between $1.6-2.0 \mathrm{~kg}$ in 105 days $(P<0.05)$.

Feed consumption and feed conversion ratios also varied significantly among the strains $(P<0.05$; Figures 2, 3, Tables 3, 4). Although FG broiler chickens consumed greater amounts of feed than the other 
strains, the FG strain was also more efficient. Total feed consumption from day 5 to day 84 was greatest for the FG genotype, followed by the M1 and M2 strains. Total feed consumption was significantly less for the slow-growing strains. A similar trend was observed in feed-conversion ratios $(P<0.05)$. Similar results were reported by Mueller et al. (2018), who found feed-conversion ratios to be 1.52 at 35 days for a fast-growing genotype and 2.43, 2.22, 2.55 and 2.46 at 63 days for slow-growing strains. Slow-growing broilers have been generally found to be relatively inefficient (Siegel, 2014; Xu et al., 2016; Brameld \& Parr, 2016; Li et al., 2017; Wen et al., 2018).

Feed consumption tended to be greater for broilers that were reared in the free-range production system from day 49 until slaughter, but the differences in feed consumption by production system were not statistically significant for any of the strains. Although feed conversion ratios did not differ significantly by production system, some differences were observed among strains. Overall, feed conversion ratios at 84 days were greatest for the S4 strain that was raised indoors and the S3 strain that was raised in the freerange system and least in for the FG strain raised in either the indoor or free-range systems. Kaya and Yildirim (2018) found no statistically significant differences in 42-day live weight, feed consumption, or feed efficiency levels of fast-growing broiler chickens reared in indoor and outdoor systems; however, both live weights and feed consumption were less for birds in the indoor system. Li et al. (2017) found birds raised in the free-range system were most efficient (feed conversion ratio $=3.07$ ), followed by those reared indoors in pens with solid floors (3.16) and those that were reared in cages (3.24).

Significant differences among strains were observed for slaughter and carcass traits (Table 5). The FG strain had the greatest carcass yield, followed by the commercial slow-growing CS, M1, and M2 strains. Carcass yields were further reduced $(P<0.05)$ in the S1, S2, S3, and S4 strains. Mueller et al. (2018) found that carcass yield decreased in connection with slower growth rates, with reported yields of $72.9 \%, 69.0 \%$, $67.0 \%, 66.0 \%$ and $62.9 \%$ for the RossPM3, SassoS1, Lohman Dual, Belgian Malinez, and Lohmann Brown Plus strains, respectively. Tasoniere et al. (2018) found a local Italian slow-growth breed to have a carcass yield of $81.8 \%-82.9 \%$ when fattened over a long period. Devatkal et al. (2018) reported carcass yields of between $69.06 \%$ and $72.20 \%$ for 4 slow-growing strains, with yield decreasing with slower growth rate. However, Cruz et al. (2018a) found carcass yields of slow-growing strains could be increased by delaying age at slaughter age, with yields ranging from $72.2 \%$ to $76.3 \%$ for 6 different strains slaughtered at 105 days of age.

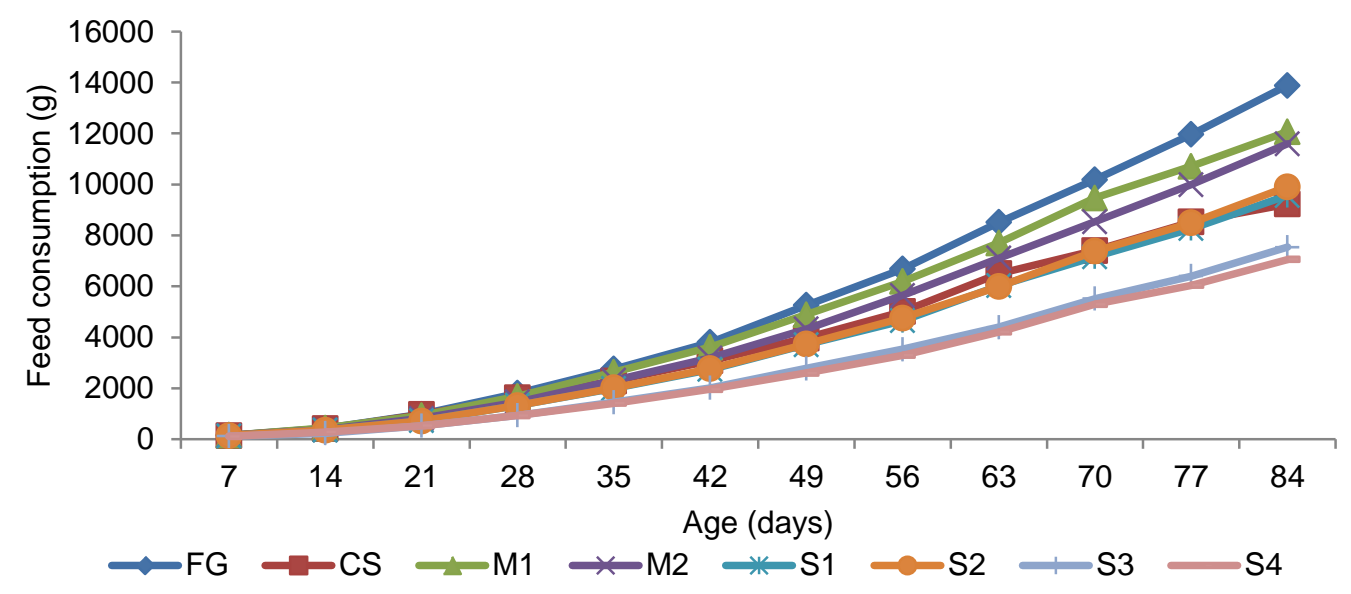

Figure 2 Feed consumption for each strain ${ }^{1}$ from 7 to 84 days of age

\footnotetext{
${ }^{1}$ FG: commercial fast-growth strain, CS: commercial slow-growth strain, M1: cross of FG and Rhode Island Red (RIR), M2: backcross of FG on Barred Plymouth Rock (BAR) x FG females, S1: FG x RIR, S2: FG x BAR, S3: FG x RIR crossed with RIR, S4: FG x BAR crossed with BAR
} 
Table 3 Daily feed consumption ( $\mathrm{g} / \mathrm{bird}$ ) by broilers of different strains from 35 to 84 days of age that were reared either indoors or with access to the outdoors

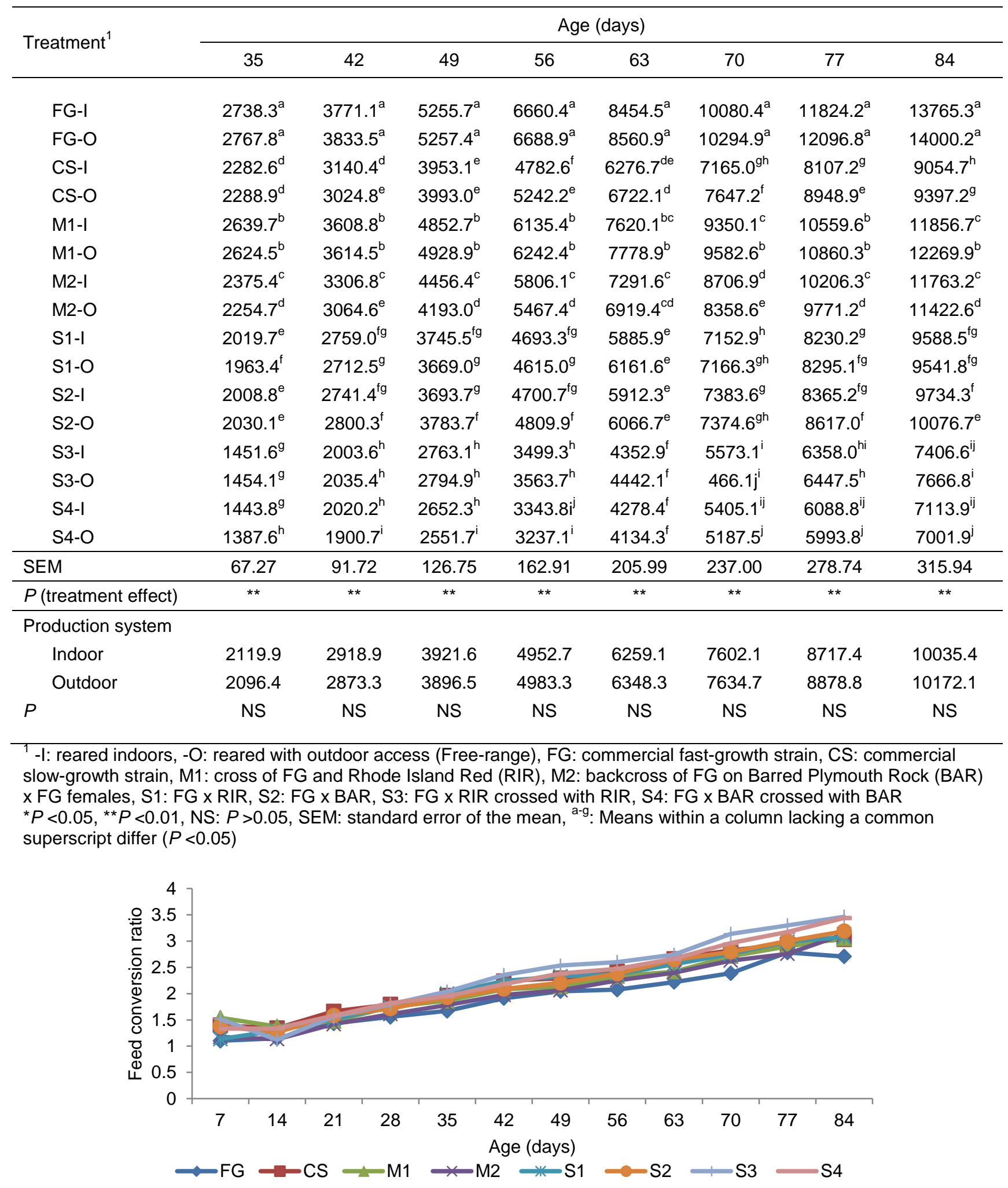

Figure 3 Feed conversion ratio for each strain ${ }^{1}$ from 7 to 84 days of age

${ }^{1}$ FG: commercial fast-growth strain, CS: commercial slow-growth strain, M1: cross of FG and Rhode Island Red (RIR), M2: backcross of FG on Barred Plymouth Rock (BAR) x FG females, S1: FG x RIR, S2: FG x BAR, S3: FG x RIR crossed with RIR, S4: FG x BAR crossed with BAR 
Table 4 Feed conversion ratio attained by broilers of different strains from 35 to 84 days of age that were reared either indoors or with access to the outdoors

\begin{tabular}{|c|c|c|c|c|c|c|c|c|}
\hline \multirow{2}{*}{ Treatment $^{1}$} & \multicolumn{8}{|c|}{ Age } \\
\hline & 35 & 42 & 49 & 56 & 63 & 70 & 77 & 84 \\
\hline FG-I & $1.64^{\mathrm{a}}$ & $1.86^{\mathrm{a}}$ & $2.03^{a}$ & $2.05^{a}$ & $2.19^{a}$ & $2.32^{\mathrm{a}}$ & $2.76^{\mathrm{ab}}$ & $2.71^{a}$ \\
\hline FG-O & $1.70^{\mathrm{a}}$ & $1.97^{\mathrm{b}}$ & $2.07^{\mathrm{ab}}$ & $2.10^{\mathrm{a}}$ & $2.25^{\mathrm{a}}$ & $2.45^{\mathrm{b}}$ & $2.81^{a b c}$ & $2.70^{\mathrm{a}}$ \\
\hline CS-I & $1.95 f^{\mathrm{fgh}}$ & $2.25^{f}$ & $2.33^{\text {gh }}$ & $2.38^{\mathrm{cd}}$ & $2.65^{\text {efgh }}$ & $2.70^{\mathrm{d}}$ & $2.89^{\text {cde }}$ & $2.89^{b}$ \\
\hline CS-O & $1.99^{h}$ & $2.23^{f}$ & $2.26^{\text {fgh }}$ & $2.47^{\mathrm{ef}}$ & $2.68^{\mathrm{fgh}}$ & $2.95^{\mathrm{fg}}$ & $2.98^{\mathrm{ef}}$ & $3.18^{\mathrm{ef}}$ \\
\hline M1-I & $1.85^{\mathrm{cd}}$ & $2.07^{\mathrm{cd}}$ & $2.15^{b c d}$ & $2.29^{b}$ & $2.38^{\mathrm{b}}$ & $2.72^{d}$ & $2.85^{\mathrm{bcd}}$ & $2.94^{\mathrm{bc}}$ \\
\hline M1-O & $1.88^{\mathrm{de}}$ & $2.09^{d}$ & $2.12^{\mathrm{abc}}$ & $2.38^{\mathrm{cd}}$ & $2.46^{\mathrm{bc}}$ & $2.70^{d}$ & $2.95^{\mathrm{def}}$ & $3.17^{\mathrm{def}}$ \\
\hline M2-I & $1.77^{\mathrm{b}}$ & $1.96^{\mathrm{b}}$ & $2.09^{\mathrm{abc}}$ & $2.26^{\mathrm{b}}$ & $2.38^{b}$ & $2.69^{d}$ & $2.79^{\mathrm{abc}}$ & $3.16^{\mathrm{def}}$ \\
\hline M2-O & $1.79^{\mathrm{bc}}$ & $1.99^{\mathrm{bc}}$ & $2.04^{\mathrm{a}}$ & $2.24^{b}$ & $2.42^{b}$ & $2.57^{\mathrm{c}}$ & $2.72^{\mathrm{a}}$ & $3.10^{\mathrm{de}}$ \\
\hline S1-I & $1.93^{\text {efgh }}$ & $2.26^{\mathrm{fg}}$ & $2.30^{g h}$ & $2.43^{\mathrm{de}}$ & $2.58^{\mathrm{de}}$ & $2.85^{\mathrm{e}}$ & $3.02^{f}$ & $3.10^{\mathrm{de}}$ \\
\hline S1-O & $2.07^{i}$ & $2.23^{\mathrm{ef}}$ & $2.36^{\mathrm{hi}}$ & $2.31^{b c}$ & $2.54^{\mathrm{cd}}$ & $2.66^{\mathrm{cd}}$ & $2.96^{\mathrm{def}}$ & $3.05^{\mathrm{cd}}$ \\
\hline S2-I & $1.89^{\text {def }}$ & $2.10^{d}$ & $2.24^{\mathrm{efg}}$ & $2.38^{\mathrm{cd}}$ & $2.68^{\text {fghi }}$ & $2.89^{\mathrm{ef}}$ & $3.14^{g}$ & $3.14^{\mathrm{def}}$ \\
\hline $\mathrm{S} 2-\mathrm{O}$ & $1.97^{g h}$ & $2.08^{d}$ & $2.17^{\text {cde }}$ & $2.37^{\mathrm{cd}}$ & $2.61^{\text {defg }}$ & $2.70^{\mathrm{d}}$ & $2.85^{\mathrm{bcd}}$ & $3.24^{\mathrm{fg}}$ \\
\hline S3-I & $1.97^{\text {gh }}$ & $2.37^{\mathrm{h}}$ & $2.54^{j}$ & $2.55^{\mathrm{g}}$ & $2.71^{\text {ghi }}$ & $3.11^{\mathrm{h}}$ & $3.36^{h}$ & $3.39^{\mathrm{h}}$ \\
\hline S3-O & $2.11^{i}$ & $2.34^{g h}$ & $2.53^{\mathrm{j}}$ & $2.65^{g}$ & $2.78^{\mathrm{hi}}$ & $3.17^{\mathrm{h}}$ & $3.24^{g}$ & $3.54^{i}$ \\
\hline S4-I & $1.99^{\mathrm{h}}$ & $2.22^{\mathrm{ef}}$ & $2.33^{\mathrm{gh}}$ & $2.53^{\mathrm{fg}}$ & $2.72^{\mathrm{hi}}$ & $3.01^{\mathrm{g}}$ & $3.20^{\mathrm{g}}$ & $3.56^{i}$ \\
\hline S4-O & $1.91^{\text {defg }}$ & $2.15^{\mathrm{de}}$ & $2.44^{\mathrm{ij}}$ & $2.41^{\mathrm{de}}$ & $2.61^{\text {def }}$ & $2.91^{\mathrm{ef}}$ & $3.15^{9}$ & $3.32^{g h}$ \\
\hline SEM & 0.01 & 0.02 & 0.02 & 0.02 & 0.02 & 0.03 & 0.02 & 0.03 \\
\hline$P$ (treatment effect) & ** & ** & ** & ** & ** & ** & ** & ** \\
\hline \multicolumn{9}{|l|}{ Production system } \\
\hline Indoor & 1.874 & 2.136 & 2.249 & 2.359 & 2.536 & 2.786 & 3.002 & 3.112 \\
\hline Outdoor & 1.927 & 2.133 & 2.247 & 2.367 & 2.543 & 2.765 & 2.958 & 3.162 \\
\hline$P$ & NS & NS & NS & NS & NS & NS & NS & NS \\
\hline
\end{tabular}

${ }^{1}$-I: reared indoors, -O: reared with outdoor access (Free-range), FG: commercial fast-growth strain, CS: commercial slow-growth strain, M1: cross of FG and Rhode Island Red (RIR), M2: backcross of FG on Barred Plymouth Rock (BAR) x FG females, S1: FG x RIR, S2: FG x BAR, S3: FG x RIR crossed with RIR, S4: FG x BAR crossed with BAR ${ }^{\star} P<0.05,{ }^{\star \star} P<0.01$, NS: $P>0.05$, SEM: standard error of the mean, ${ }^{a-g}$ : Means within a column lacking a common superscript differ $(P<0.05)$

In this study, the ratio of edible internal organs to carcass weight was significantly $(P<0.05)$ greater in the S3 and S4 strains in comparison to the S1, S2, M2, M1, CS, and FG strains (Table 5), whereas abdominal fat percentages (g AF/g LW) were significantly $(P<0.05)$ less in the S3 $(1.5 \%)$ and S4 $(2.0 \%)$ strains (Table 5). These traits are closely related to growth rate, findings which are consistent with results reported in other studies (Li et al., 2017; Mueller et al., 2018).

The ratio of breast meat to carcass weight was greatest in the FG genotype, followed by the M2, M1, CS, S2 and S1 strains, and finally by the S3 and S4 strains (Table 5). By contrast, thigh-meat ratios were greatest for the slow-growing S3 and S4 strains, followed by the CS, S2, M2, M1, and S1 strains with the FG strain having the least thigh meat as a percentage of carcass weight (Table 5). Mueller et al. (2018) similarly reported greater breast- and lower thigh-meat ratios in commercial fast-growing strains and lower breastand greater thigh-meat ratios in slow-growing strains. In their study conducted with 6 different strains, Cruz et al. (2018a) found breast-meat ratios ranged between $21.2 \%-24.4 \%$, with significant $(P<0.05)$ increases in ratios observed in line with increases in growth; while the authors also reported decreases in thigh-meat ratios $(29.3 \%$ to $31.0 \%)$ with increases in growth, these differences were not statistically significant. Tasoniere et al. (2018) reported breast ratios of $13.3 \%$ and $13.9 \%$ and thigh ratios of $25.3 \%$ and $25.6 \%$ in 2 local Italian strains with very low growth rates. These ratios are lower than all those obtained in the present study. Devatkal et al. (2018) reported that thigh and breast ratios varied with the level of development of slow-growing strains (thigh: $15.57 \%$ and $13.54 \%$; breast: $22.94 \%$ and $20.98 \%$, at 90 days of age). 
Table 5 Carcass traits for broilers of different strains at 84 days of age that were reared either indoors or with access to the outdoors

\begin{tabular}{|c|c|c|c|c|c|c|c|}
\hline \multirow{2}{*}{ Treatment $^{1}$} & \multirow{2}{*}{ CY (\%) } & \multirow{2}{*}{ EIO (\%) } & \multirow{2}{*}{ AF (\%) } & \multicolumn{2}{|c|}{ Breast } & \multicolumn{2}{|c|}{ Thigh } \\
\hline & & & & Yield (\%) & $\mathrm{Ph}$ & Yield (\%) & $\mathrm{Ph}$ \\
\hline FG-I & $75.4^{\mathrm{a}}$ & $4.3^{f}$ & $2.9^{\text {abcdef }}$ & $37.5^{\mathrm{a}}$ & $5.6^{\mathrm{bcd}}$ & $27.2^{\mathrm{b}}$ & $5.8^{\mathrm{c}}$ \\
\hline FG-O & $73.8^{\mathrm{ab}}$ & $4.6^{\mathrm{def}}$ & $2.9^{\text {abcdef }}$ & $37.1^{\mathrm{a}}$ & $5.6^{\mathrm{bcd}}$ & $27.3^{\mathrm{b}}$ & $5.8^{c}$ \\
\hline CS-I & $73.6^{\mathrm{ab}}$ & $4.8^{\text {cdef }}$ & $2.5^{\text {bcdef }}$ & $30.9^{\mathrm{bcd}}$ & $5.5^{\mathrm{d}}$ & $30.8^{\mathrm{a}}$ & $5.8^{\mathrm{bc}}$ \\
\hline CS-O & $70.0^{\mathrm{ab}}$ & $4.5^{\mathrm{def}}$ & $2.8^{\text {abcdef }}$ & $31.0^{\mathrm{bc}}$ & $5.5^{\mathrm{d}}$ & $31.1^{\mathrm{a}}$ & $5.9^{b c}$ \\
\hline M1-I & $71.5^{\text {bcde }}$ & $4.9^{\text {cdef }}$ & $3.7^{\mathrm{abc}}$ & $31.6^{\mathrm{bc}}$ & $5.6^{\mathrm{bcd}}$ & $28.8^{\mathrm{ab}}$ & $5.9^{b c}$ \\
\hline M1-O & $72.0^{\mathrm{abcd}}$ & $4.8^{\text {cdef }}$ & $3.5^{\mathrm{abcd}}$ & $30.1^{\text {bcde }}$ & $5.6^{\mathrm{bcd}}$ & $29.4^{\mathrm{ab}}$ & 5. $9^{\mathrm{bc}}$ \\
\hline M2-I & $72.2^{\mathrm{abc}}$ & $4.9^{\text {cdef }}$ & $2.7^{\text {abcdef }}$ & $31.9^{b}$ & $5.8^{\mathrm{ab}}$ & $29.7^{\mathrm{ab}}$ & $6.3^{\mathrm{a}}$ \\
\hline M2-O & $71.5^{\text {bcde }}$ & $5.2^{\text {cde }}$ & $2.6^{\text {abcdef }}$ & $32.6^{\mathrm{b}}$ & $5.7^{\mathrm{abc}}$ & $30.1^{\mathrm{ab}}$ & $5.9^{b c}$ \\
\hline S1-I & $68.9^{\text {cdef }}$ & $5.4^{\mathrm{cd}}$ & $4.4^{\mathrm{a}}$ & $30.4^{\text {bcde }}$ & $5.7^{\mathrm{abc}}$ & $29.5^{\mathrm{ab}}$ & $5.9^{\mathrm{bc}}$ \\
\hline S1-O & $69.6^{\text {cde }}$ & $5.5^{\mathrm{cd}}$ & $3.3^{\text {abcde }}$ & $28.6^{\text {cdef }}$ & $5.6^{\mathrm{bcd}}$ & $29.9^{\mathrm{ab}}$ & $5.8^{c}$ \\
\hline S2-I & $71.5^{\text {bcde }}$ & $4.9^{\text {cdef }}$ & $4.0^{\mathrm{ab}}$ & $30.5^{\mathrm{bcde}}$ & $5.8^{\mathrm{ab}}$ & $30.6^{\mathrm{a}}$ & $6.0^{\mathrm{b}}$ \\
\hline S2-O & $68.1^{\text {ef }}$ & $5.6^{\mathrm{bc}}$ & $4.2^{\mathrm{ab}}$ & $30.4^{\text {bcde }}$ & $5.7^{\mathrm{abc}}$ & $30.1^{\mathrm{ab}}$ & $5.9^{\mathrm{bc}}$ \\
\hline S3-I & $68.2^{\text {def }}$ & $7.6^{\mathrm{a}}$ & $1.5^{\mathrm{ef}}$ & $26.1^{\dagger}$ & $5.7^{\mathrm{abc}}$ & $31.5^{\mathrm{a}}$ & $6.0^{\mathrm{b}}$ \\
\hline S3-O & $65.7^{f}$ & $7.9^{\mathrm{a}}$ & $1.5 f$ & $26.3^{f}$ & $5.6^{\mathrm{bcd}}$ & $31.5^{\mathrm{a}}$ & $6.0^{\mathrm{b}}$ \\
\hline S4-I & $65.6^{\dagger}$ & $6.5^{\mathrm{b}}$ & $1.8^{\mathrm{def}}$ & $27.9^{\text {def }}$ & $5.7^{\mathrm{abc}}$ & $31.3^{\mathrm{a}}$ & $6.0^{\mathrm{b}}$ \\
\hline S4-O & $67.6^{\text {ef }}$ & $6.4^{\mathrm{b}}$ & $2.2^{\text {cdef }}$ & $27.7^{\text {ef }}$ & $5.8^{\mathrm{ab}}$ & $31.3^{\mathrm{a}}$ & $6.0^{b}$ \\
\hline SEM & 0.327 & 0.094 & 0.111 & 0.289 & 0.128 & 0.175 & 0.015 \\
\hline$P$ (treatment effect) & ** & ** & ** & ** & ** & ** & ** \\
\hline \multicolumn{8}{|l|}{ Production System } \\
\hline Indoor & 71.58 & 5.41 & 2.94 & 30.86 & 5.67 & 29.94 & 5.67 \\
\hline Outdoor & 71.24 & 5.57 & 2.87 & 30.49 & 5.62 & 30.11 & 5.62 \\
\hline$P$ & NS & NS & NS & NS & * & NS & * \\
\hline
\end{tabular}

1 -I: reared indoors, -O: reared with outdoor access (Free-range), FG: commercial fast-growth strain, CS: commercial slow-growth strain, M1: cross of FG and Rhode Island Red (RIR), M2: backcross of FG on Barred Plymouth Rock (BAR) x FG females, S1: FG x RIR, S2: FG x BAR, S3: FG x RIR crossed with RIR, S4: FG x BAR crossed with BAR $\mathrm{CY}$ : Cold carcass yield, EIO: Edible inner organs, AF:Abdominal fat ${ }^{\star} P<0.05,{ }^{* \star} P<0.01, \mathrm{NS}: P>0.05$, SEM: standard error of the mean, ${ }^{\mathrm{a}-\mathrm{g}}$ : Means within a column lacking a common superscript differ $(P<0.05)$

In this study, carcass yield was not significantly affected by production system, although yields were somewhat greater in the free-range system as compared to the indoor system. Previous studies have reported conflicting results regarding the effects of production system on carcass yields and various carcass traits. Kaya and\& Yildirim (2018) reported carcass yields, breast ratios, and thigh ratios of fast-growth chickens raised in an indoor system to be $78.99 \%, 36.58 \%$, and $27.64 \%$, respectively, as compared to $77.94 \%, 36.45 \%$, and $26.57 \%$, respectively, for those raised in an outdoor system; however, these differences between production systems were not statistically significant. The same study reported edible internal organ ratios $(8.52 \%-8.73 \%)$ percentages that are greater than those that were observed in this study. Who-Ming et al. (2018) also reported breast ratios of chickens raised indoors to be greater than those raised outdoors; however, thigh ratios were greater for those raised outdoors as compared to indoors. Fanatico et al. (2005) found no difference between indoor and outdoor systems in terms of $\mathrm{pH}$ and colour values, and Li et al. (2017) reported similar results for cage, ground, and free-range systems in terms of carcass yields $(67.8 \%, 69.1 \%$, and $68.5 \%$, respectively), abdominal fat $(7.18 \%, 7.56 \%$, and $5.26 \%$, respectively), breast ratios $(17.05 \%, 18.89 \%$, and $17.98 \%$, respectively), and thigh ratios $(20.32 \%, 19.17 \%$, and $19.76 \%$, respectively). 
Breast $\mathrm{pH}$ values ranged between 5.6 and 5.8 and thigh $\mathrm{pH}$ values between 5.8 and 6.30 , with greater values found in the slow-growing S4, S3 and S2 and medium-growing M1 strains (Table 5). Similar to the present results, Tasoniere et al. (2016) found breast pH values of 5.87 and 6.87 at 48 hours after slaughter. Devatkal et al. (2018) reported breast pH levels between 6.20 and 6.68 for different strains, which indicate less acidic meat than was observed here. Cruz et al. (2018b) found $\mathrm{pH}$ values of 5 slow-growing strains to range between 5.75 and 6.03 for breast meat and between 6.02 and 6.36 for thigh meat.

Breast and thigh $L^{*}, a^{*}$ and $b^{*}$ colour values varied among strains with different growth rates $(P<0.05$; Table 6). Whereas, Tasoniere et al. (2016) observed less intense colour values for breast meat ( $L^{*}: 50.0$ and 49.8; $a^{*}$ : -1.41 and 1.03; $b^{*}: 6.73$ and 6.90) than were observed here. Cruz et al. (2018b) observed no significant differences in colour values of either breast or thigh meat among 5 slow-growing strains.

Table 6 Colour values for breast and thigh meat of broilers of different strains at 84 days of age that were reared either indoors or with access to the outdoors

\begin{tabular}{|c|c|c|c|c|c|c|}
\hline \multirow{2}{*}{ Treatment $^{1}$} & \multicolumn{3}{|c|}{ Breast } & \multicolumn{3}{|c|}{ Thigh } \\
\hline & $L^{*}$ & $a^{*}$ & $b^{\star}$ & $L^{*}$ & $a^{*}$ & $b^{\star}$ \\
\hline FG-I & $61.1^{\text {abcde }}$ & $2.1^{\mathrm{a}}$ & $8.2^{\mathrm{a}}$ & $56.5^{\mathrm{ab}}$ & $2.5^{\mathrm{b}}$ & $7.4^{\mathrm{a}}$ \\
\hline FG-O & $61.2^{\text {abcde }}$ & $2.2^{\mathrm{a}}$ & $8.0^{\mathrm{a}}$ & $58.5^{a}$ & $2.5^{\mathrm{b}}$ & $7.3^{\mathrm{a}}$ \\
\hline CS-I & $62.2 \mathrm{abc}$ & $2.0^{\mathrm{a}}$ & $3.9^{b}$ & $57.4^{\mathrm{a}}$ & $5.2^{\mathrm{a}}$ & $3.2^{\mathrm{b}}$ \\
\hline CS-O & $61.1^{\text {abcde }}$ & $1.4^{\mathrm{a}}$ & $3.7^{\mathrm{b}}$ & $58.2^{\mathrm{a}}$ & $5.0^{\mathrm{a}}$ & $2.3^{\mathrm{b}}$ \\
\hline M1-I & $59.6^{\text {abcde }}$ & $2.2^{\mathrm{a}}$ & $7.7^{\mathrm{a}}$ & $56.2^{\mathrm{ab}}$ & $2.4^{\mathrm{b}}$ & $7.9^{\mathrm{a}}$ \\
\hline M1-O & $61.0^{\text {abcde }}$ & $2.2^{\mathrm{a}}$ & $7.9^{\mathrm{a}}$ & $55.3^{\mathrm{abc}}$ & $2.1^{\mathrm{b}}$ & $7.5^{\mathrm{a}}$ \\
\hline M2-I & $61.7^{\mathrm{abcd}}$ & $2.2^{\mathrm{a}}$ & $7.8^{\mathrm{a}}$ & $51.9^{c}$ & $1.9^{\mathrm{b}}$ & $6.3^{\mathrm{a}}$ \\
\hline M2-O & $60.1^{\text {abcde }}$ & $2.0^{\mathrm{a}}$ & $8.7^{\mathrm{a}}$ & $55.6^{\mathrm{abc}}$ & $2.1^{\mathrm{b}}$ & $7.1^{\mathrm{a}}$ \\
\hline S1-I & $59.7^{\text {abcde }}$ & $2.0^{\mathrm{a}}$ & $7.4^{\mathrm{a}}$ & $55.7^{\mathrm{abc}}$ & $2.2^{\mathrm{b}}$ & $6.6^{\mathrm{a}}$ \\
\hline S1-O & $63.0^{\mathrm{a}}$ & $2.2^{\mathrm{a}}$ & $8.2^{\mathrm{a}}$ & $56.5^{\mathrm{ab}}$ & $1.9^{b}$ & $6.9^{\mathrm{a}}$ \\
\hline S2-I & $57.2^{\mathrm{de}}$ & $2.0^{\mathrm{a}}$ & $7.0^{\mathrm{a}}$ & $53.1^{\mathrm{bc}}$ & $2.1^{\mathrm{b}}$ & $7.1^{\mathrm{a}}$ \\
\hline $\mathrm{S} 2-\mathrm{O}$ & $58.2^{\text {bcde }}$ & $2.0^{\mathrm{a}}$ & $7.7^{\mathrm{a}}$ & $54.5^{\mathrm{abc}}$ & $2.1^{\mathrm{b}}$ & $7.5^{\mathrm{a}}$ \\
\hline S3-I & $62.8^{\mathrm{ab}}$ & $2.2^{\mathrm{a}}$ & $8.1^{\mathrm{a}}$ & $55.5^{\mathrm{abc}}$ & $2.2^{\mathrm{b}}$ & $6.6^{\mathrm{a}}$ \\
\hline S3-O & $62.2^{\mathrm{abc}}$ & $2.2^{\mathrm{a}}$ & $8.7^{\mathrm{a}}$ & $54.5^{\mathrm{abc}}$ & $2.1^{\mathrm{b}}$ & $7.3^{\mathrm{a}}$ \\
\hline S4-I & $56.9^{\mathrm{e}}$ & $2.0^{\mathrm{a}}$ & $7.7^{\mathrm{a}}$ & $54.7^{\mathrm{abc}}$ & $2.1^{\mathrm{b}}$ & $7.5^{\mathrm{a}}$ \\
\hline S4-O & $57.9^{\text {cde }}$ & $1.6^{\mathrm{a}}$ & $8.1^{\mathrm{a}}$ & $55.7^{\mathrm{abc}}$ & $2.2^{\mathrm{b}}$ & $8.1^{\mathrm{a}}$ \\
\hline SEM & 0.267 & 0.055 & 0.150 & 0.241 & 0.102 & 0.151 \\
\hline$P$ (treatment effect) & ** & NS & $\star \star$ & ** & ** & ** \\
\hline \multicolumn{7}{|l|}{ Production System } \\
\hline Indoor & 60.17 & 2.12 & 7.23 & 55.12 & 2.59 & 6.59 \\
\hline Outdoor & 60.61 & 1.96 & 7.63 & 56.08 & 2.51 & 6.75 \\
\hline$P$ & NS & NS & NS & * & NS & NS \\
\hline \multicolumn{7}{|c|}{$\begin{array}{l}{ }^{1} \text {-l: reared indoors, -O: reared with outdoor access (Free-range), FG: commercial fast-growth strain, CS: commercial } \\
\text { slow-growth strain, M1: cross of FG and Rhode Island Red (RIR), M2: backcross of FG on Barred Plymouth Rock (BAR) } \\
\times \text { FG females, S1: FG } x \text { RIR, S2: FG x BAR, S3: FG x RIR crossed with RIR, S4: FG x BAR crossed with BAR } \\
{ }^{*} P<0.05,{ }^{\star *} P<0.01, N S: P>0.05, S E M: \text { standard error of the mean, }{ }^{a-g} \text { : Means within a column lacking a common } \\
\text { superscript differ }(P<0.05) \\
L^{*} \text { : lightness; } a^{\star} \text { : Redness; } b^{\star} \text { : Yellowness }\end{array}$} \\
\hline
\end{tabular}

An important finding of the present study is the significant differences observed among strains in use of the outdoor environment when it was made available. Between days $29-84$, the level of outdoor access was only $18 \%$ for the FG genotype, compared to $65 \%, 54 \%, 57 \%, 67 \%, 69 \%, 94 \%$, and $98 \%$, respectively, for the M1, M2, CS, S1, S2, S3, and S4 strains. Fanatico et al. (2016) reported outdoor access rates of $12.9 \%$ for broiler chicks aged $7-10$ weeks. Studies of broiler behaviour have reported wide variations in 
outdoor access (Riber et al., 2018), which is negatively affected by factors such as bad weather conditions, especially rain, high winds, and high levels of sunlight radiation (Dawkins et al., 2003; Jones et al., 2007; Stadig et al., 2017), ground conditions of the outdoor environment, and the size of the enclosed area (Stadig et al., 2017) in addition to genotype (Castellini et al., 2016). Lichovnikova et al. (2017) have stated that fastgrowing broiler chickens are unable to make use of the outdoor access provided by organic and free-range production systems because their heavy bodies limit their ability to move.

In the present study, mortality during the first four weeks of the rearing period varied between $0.5 \%$ $1.5 \%$ for the different strains, with the greatest mortality observed in the FG genotype (1.5\%), followed by the $\mathrm{M} 2$ and CS (1.4\% and 1.2\%) strains. M1, S1, S2, S3, and S4 strains had less mortality $(1.0 \%, 1.0 \%, 0.8 \%$, $0.8 \%$, and $0.8 \%$, respectively). After four weeks, once chicks were given access to the outdoor environment (days 29-84), mortality rate increased to $2.5 \%$ in the FG genotype and $1.5 \%$ in the M1, M2, CS, S2, and S4 strains; however, mortality rates decreased to $0.0 \%$ in the S1 and S3 strains. According to Bessei (2006), mortality rates are lower in slow-growing strains than in faster-growing strains. Tasoniere et al. (2018) reported mortality rates ranging between $5.3 \%$ and $12.8 \%$ for 2 slow-growing strains of Italian broilers from 29 days after hatching through 72 days of age. Mortality rates vary greatly between studies and are very closely related to growth and health conditions. Rapidly growing strains are more susceptible to the sudden death syndrome (Grashorn et al., 1998) and ascites (Deeb et al., 2002) than their slower growing counterparts.

In free-range poultry production systems, the birds can be affected by climatic conditions such as rain, wind and sunlight levels; types and amounts of outdoor-area vegetation, insects and other living organisms; size of the free-range area and access to it; mobility; and genotype (Fanatico et al., 2016). In this study, indoor ventilation was provided, and environmental effects are assumed to be minimal due to low levels of wind and rain ( 5 windy days, 7 rainy days and 11 cloudy days without rainfall) and moderate temperatures $\left(15-32^{\circ} \mathrm{C}\right)$.

\section{Conclusions}

Differences in production system (indoor vs free-range) did not significantly affect the feed efficiency and carcass traits of the commercial and crossbred chicken strains in this study. However, strains characterized as having different growth rates varied in their use of the outside area available in the freerange system. Thus, strains that are characterized by high genetic potential for growth are not recommended for use in free-range and organic production systems.

\section{Acknowledgements}

The study was supported by Ondokuz Mayis University Project Office (Project number: PYO.ZRT.1905-10001).

\section{Authors' Contributions}

MS, USY and MAB designed the study and collected to all of performance and carcass traits data. MS performed to statistical analysis. All the authors made substantial contributions to writing and revising the manuscript.

\section{Conflicts of interest:}

The authors declare that they have no conflict of interest.

\section{References}

Bessei, W., 2006. Welfare of broilers: a review. World's Poult. Sci. J., 62, 455-466

Boz, M.A., Sarıca, M. \& Yamak, U.S., 2017. Effect of production system on foot pad dermatitis (FPD) and plumage quality of geese. Europ. Poult.Sci. 81. ISSN 1612-9199. Verlag Eugen Ulmer. Stuttgart. DOI: 10.1399/eps.2017.216.

Brameld, J.M. \& Parr, T., 2016. Improving efficiency in meat production. Proc. Nutr. Soc. 75, 242-246.

Castellini, C.C., Mugnai, L., Moscati, S., Mattioli, M.G., Amato, A.C. \& Mancinelli, A., 2016. Adaptation to organic rearing system of eight different chicken genotypes: behaviour, welfare and performance. Ital. J. Anim. Sci. 15, 37-46.

Chen, X., Jiang, W., Tan, H.Z., Xu, G.F., Zhang, X.B., Wei, S. \& Wang, X.Q., 2013. Effects of outdoor access on growth performance, carcass composition, and meat characteristics of broiler chickens. Poult. Sci. 92, 435-443.

Cruz, F.L., Vieira-Saraiva, L.K., Silva, G.E., Nogueira, T.M., Silva, A.P. \& Faria, P.B., 2018a. Growth and carcass characteristics of different crosses of broiler chickens reared under an alternative system. Semina: Ciências Agrárias, Londrina, 39, 317-328.

Cruz, F.L., Silva, A.A., Machado, I.F.M., Vieira, L.C., Esteves, C., Fassani, E.J. \& Faria, P.B., 2018b. Meat quality of chicken of different crossings in alternative system. Arq. Bras. Med. Vet. Zootec., 70, 254-262.

Dawkins, M.S., Cook, P.A., Whittingham, M.J., Mansell, K.A. \& Harper, A.E., 2003. What makes free-range broiler chickens range? In situ measurement of habitat preference. Anim. Behav. 66, 151-160.

Deeb, N., Shlosberg, A. \& Cahaner, A., 2002. Genotype-by-environment interaction with broiler genotypes differing in growth rate. 4. Association between responses to heat stress and to cold-induced ascites. Poult. Sci. 81, 14541462. 
Devatkal, S.K., Vishnuraj, M.R., Kulkarni, V.V. \& Kotaiah, T., 2018. Carcass and meat quality characterization of indigenous and improved variety of chicken genotypes. Poult. Sci. 97, 2947-2956.

Fanatico, A.C., Pillai, P.B., Cavitt, L.C., Owens, C.M. \& Emmert, J.L., 2005. Evaluation of slower-growing broiler genotypes grown with and without outdoor access: Growth performance and carcass yield. Poult. Sci. 84, 13211327.

Fanatico, A.C., Pillai, P.B., Cavitt, L.C., Emmert, J.L., Meullenet, J.F. \& Owens, C.M., 2006. Evaluation of slower-growing broiler genotypes grown with and without outdoor access: Sensory attributes. Poult. Sci. 85,337-343.

Fanatico, A.C., Pillai, P.B., Emmert, J.L., Gbur, E.E., Meullenet, J.F. \& Owens, C.M., 2007. Sensory attributes of slowand fast-growing chicken genotypes raised indoors or with outdoor access. Poult. Sci. 86, 2441-2449.

Fanatico, A.C., Mench, J.A., Archer, G.S., Liang,Y., Brewer-Gunsaulis, V.B., Owens, C.M. \& Donoghue, A.M., 2016. Effect of outdoor structural enrichments on the performance, use of range area, and behavior of organic meat chickens. Poult. Sci. 95, 1980-1988.

Fossum, O., Jansson, D.S., Etterlin, P.E. \& Vågsholm, I., 2009. Causes of mortality in laying hens in different housing systems in 2001 to 2004. Acta Veterinaria Scandinavica. 51, 1-9.

Franco, D., Rois, D., Vazquez, J.A. \& Lorenzo, J.M., 2013. Carcass morphology and meat quality from roosters slaughtered at eight months affected by genotype and finishing feeding. Spanish J. Agric. Res. 11, 382-393.

Gordon, S.H. \& Charles, D.R., 2002. Niche and Organic Chicken Products. Nottingham University Press, Nottingham, UK.

Grashorn, M., Bessei, W., Thiele, H.A. \& Seemann, G., 1998. Inheritance of Troponin T levels in meat-type chicken. Archiv für Geflügelkunde. 62, 283-286.

Hardy, B., Crilly, N., Pendleton, S., Andino, A., Wallis, A., Zhang, N. \& Hanning, I., 2013. Impact of rearing conditions on the microbiological quality of raw retail poultry meat. J. Food Sci. 78, 1232-1235.

Jones, M. \& Millis, A.D., 1999. Divergent selection for social reinstatement and behaviors in Japanese quail: Effects on sociality and social discrimination. Poult. Avian Biol. Rev. 10, 213-223.

Jones, T., Feber, R., Hemery, G., Cook, P., James, K., Lamberth, C. \& Dawkins, M., 2007. Welfare and environmental benefits of integrating commercially viable free-range broiler chickens into newly planted woodland: A UK case study. Agric. Syst. 94, 177-188.

Kaya, S. \& Yildirim, H., 2018. Effects of a semi-intensive raising system on growth performance, carcass traits and meat quality of broiler chicks. Indian J. Anim. Sci. 52, 309-313.

Lewis, P.D., Perry, G.C., Farmer, L.J. \& Patterson, R.L.S., 1997. Responses of two genotypes of chicken to the diets and stocking densities typical of UK and "label rouge" systems: I. Performance, behaviour and carcass composition. Meat Sci. 45, 501-516.

Li, Y., Luo, C., Wang, J. \& Guo, F., 2017. Effects of different raising systems on growth performance, carcass, and meat quality of medium-growing chickens. J. App. Anim. Res., 45, 326-330.

Lichovnikova, M., Hample, D., Nemodova, S., Kupcikova, L. \& Anderle, V., 2017. J. Central Eor. Agric., 18, $632-645$.

Marin, R.H., Fretes, P., Gusman, D. \& Jones, R.B., 2001. Effects of an acute stressor on fear and on the social reinstatement responses of domestic chicks to cage mates and strangers. Appl. Anim. Behav. Sci. 71, 57-66.

Martinez-Perez, M., Sarmiento-Franco, L., Santos-Ricalde, R.H. \& Sandoval, C., 2017. Poultry meat production in freerange systems: perspectives for tropical areas. World's Poult. Sci. J., 73, 1-11.

Mendl, M., 1999. Performing under pressure: Stress and cognitive function. Appl. Anim. Behav. Sci. 65, $221-224$.

Mikulski, D., Celej, J., Jankowski, J., Majewska, T. \& Mikulskaet, M., 2011. Growth performance, carcass traits and meat quality of slower-growing and fast-growing chickens raised with and without outdoor access. Asian-Austral. J. Anim. Sci., Seoul, 24(10),1407- 1416, 2011.

Ming, W., Arsi, K., Moyle, J.R., Gaunsalis, V.B., Owens, C.M., Clark, F.D., Fanatico, A., Upadhyay, A., Donoghue, D.J. \& Donoghue, A.M., 2018. Meat quality characteristics of fast-growing broilers reared under different types of pasture management: Implications for organic and alternative production systems (Part II). J. Appl. Poult. Res. 27, 215222.

Mueller, S., Kreuzer, M., Siegrist, M., Mannale, K., Messikommer, R.E. \& Gangnat, I.D.M., 2018. Carcass and meat quality of dual-purpose chickens (Lohmann Dual, Belgian Malines, Schweizerhuhn) in comparison to broiler and layer chicken types. Poult. Sci. 97, 3325-3336.

National Research Council (NRC), 1994. National Research Council, Nutrient Requirements of Poultry. 9th rev. ed. National Academy Press, Washington, DC.

Riber, A.B., Van de Weerd, H.A., De Jong, I.C. \& Steenfeldt, S., 2018. Review of environmental enrichment for broiler chickens. Poult. Sci. 97, 378-396.

Rodenburg, T.B., Tuyttens, F.A.M., De Reu, K., Herman, L., Zoons, J. \& Sonck, B., 2008. Welfare assessment of laying hens in furnished cages and non-cage systems: an on-farm comparison. Animal Welfare 17, 363-373.

Sarica, M. \& Yamak, U.S., 2010. Developing slow-growing meat chickens and their properties. Anadolu J. Agric.Sci. 25, 61-67.

Sarica, M., Ocak, N., Turhan, S., Kop, C. \& Yamak, U.S., 2011. Evaluation of meat quality from 3 turkey genotypes reared with or without outdoor Access. Poult. Sci. 90, 1313-1323.

Sarica, M., Yamak, U.S., Turhan, S., Boz, M.A., Saricaoglu \& Altop, A., 2014. Comparing slow-growing chickens produced by two- and three-way crossings with commercial genotypes. 2. Carcass quality and blood parameters. Europ. Poult. Sci. 78.

Sarica, M., Ceyhan, V., Yamak, U.S., Uçar, A. \& Boz, M.A., 2016. Comparison of slow growing synthetic broiler genotypes with commercial broilers in terms of growth, carcass traits and some economic parameters. J. Agric. Sci. 22, 20-31. 
Sekeroglu, A., Demir, E. Sarica, M. \& Ulutas, Z., 2009. Effect of housing system on growth performance, blood plasma constituents and meat fatty acids in broiler chickens. Pakistan J. Bio. Sci. 12(8), 631-636.

Semwogerere, F., Neethling, J., Muchenje, V. \& Hoffman, L.C., 2018. Effects of production systems on the carcass and meat quality characteristics of spent laying hens. Poult. Sci., 97, 1990-1997.

Siegel, P.B., 2014. Evolution of the modern broiler and feed efficiency. Annu. Rev. Anim. Biosci. 2, 375-385.

Spencer, T., 2013. Pastured poultry nutrition and forages. National Sustainable Agriculture Information Service. Accessed Aug. 2017. Available from: http://www.sare.org/content/download/73280/1060790/Pastured Poultry Nutrition and Forages.pdf.

Stadig, L.M., Rodenburg, T.B., Ampe, B., Reubens, B. \& Tuyttens, F.A.M., 2017. Effects of shelter type, early environmental enrichment and weather conditions on free-range behaviour of slow-growing broiler chickens. Animal 11, 1046-1053.

Tasonieroa, G., Cullerea, M., Baldanb, G. \& Zottea, A.D., 2018. Productive performances and carcase quality of male and female Italian Padovana and Polverara slow-growing chicken breeds. Italian J. Anim. Sci. 17, 530-539.

Tuyttens, F., Heyndrickx, M., De Boeck, M., Moreels, A., Van Nuffel, A., Van Poucke, E., Van Coillie, E., Van Dongen, S. \& Lens, L., 2008. Broiler chicken health, welfare and fluctuating asymmetry in organic versus conventional production systems. Livest. Sci. 113, 123-132.

Van Loo, E., Caputo, V., Nayga, R.M., Meullenet, J.F., Crandall, P.G. \& Ricke, S.C., 2010. Effect of organic poultry purchase frequency on consumer attitudes toward organic poultry meat. J. Food Sci. 75, 384-397.

Wang, K.H., Shi, S.R., Dou, T.C. \& Sun, H.J., 2009. Effect of a free-range raising system on growth performance, carcass yield, and meat quality of slow-growing chicken. Poult. Sci. 88, 2219-2223.

Wen, C., Yan, W., Zheng, J., Ji, C., Zhang, D., Sun, C. \& Yang, N., 2018. Feed efficiency measures and their relationships with production and meat quality traits in slower growing broilers. Poult. Sci. 97, 2356-2364.

Widowski, T., Classen, H., Newberry, R., Petrik, M., Schwean-Lardner, K., Cottee, S. \& Cox, B., 2013. Code of practice for the care and handling of pullets, layers and spent fowl: Poultry (layers). Review of scientific research on priority areas.

Xu, Z., Ji, C., Zhang, Y., Zhang, Z., Nie, Q., Xu, J., Zhang, D. \& Zhang, X., 2016. Combination analysis of genome-wide association and transcriptome sequencing of residual feed intake in quality chickens. BMC Genomics. 17, 594.

Yamak, U.S., Sarica, M. \& Boz, M.A., 2014. Comparing slow-growing chickens produced by two- and three-way crossings with commercial genotypes. 1. Growth and carcass traits. Europ. Poult. Sci. 78.

Yang, N. \& Jiang, R.S., 2005. Recent advances in breeding for quality chickens. World's Poult. Sci. J. 61, 373-381. 